\title{
PANORAMA DA INDÚSTRIA DE CELULOSE E PAPEL NO BRASIL: 2001 a 2011
}

\author{
Maritzel Rios Fuentes Coelho ${ }^{1}$, Márcio Henrique Coelho ${ }^{2}$ \\ ${ }^{1}$ Economista, Dr ${ }^{\mathrm{a}}$., Curitiba, PR, Brasil - maritzel@ig.com.br \\ ${ }^{2}$ Economista, Dr., Depto. de Economia, UEPG, Ponta Grossa, PR, Brasil - marhenco@ig.com.br \\ Recebido para publicação: 27/07/2012 - Aceito para publicação: 11/06/2013
}

\begin{abstract}
Resumo
Este artigo visa estabelecer um panorama da indústria de celulose e papel sediada no Brasil, evidenciando o desempenho de algumas variáveis importantes para análise do setor, tais como a capacidade de produção, os tipos de produtos, as magnitudes das exportações e das importações e o destino das exportações, o nível e a capacidade de utilização e o preço médio das exportações no período de 2001 a 2011. Para tanto, foram utilizados dados do Ministério do Desenvolvimento, Indústria e Comércio Exterior (MDIC, 2012), da Associação Brasileira de Celulose e Papel (BRACELPA, 2011) e da Organização das Nações Unidas para Alimentação e Agricultura (FAO, 2011). No geral, os resultados revelam que a indústria de celulose vem ganhando espaço no âmbito do comércio internacional, diante de uma nova redistribuição espacial da produção, em função do obsoletismo das indústrias europeias, norte-americanas e canadenses e da inserção da celulose de fibra curta nos diferentes estágios de produção. No caso da indústria de papel, os indicadores apontam um cenário não tão promissor, diante do acirramento da concorrência internacional, embora o mercado interno possa vir a se constituir num grande impulso para a indústria local.

Palavras-chave: Florestas; economia florestal; exportações; comércio internacional.
\end{abstract}

\begin{abstract}
Overview of the pulp and paper industry in Brazil: 2001/2011. This research aims to analyze the performance of the Brazilian pulp and paper industry, from 2001 to 2011, towards the main variables for the sector analysis, such as production capacity, sort of products, magnitude of exports, imports, destination of exports, level and capacity of utilization, and the average price of exports. In order to that, it used primary data from Ministry of Development, Industry and Foreign Trade (MDIC, 2012), Brazilian Association of Pulp and Paper (BRACELPA, 2011) and Food and Agriculture Organization of the United Nations (FAO, 2011). In general, results indicate that cellulose industry has gained importance in international trade, before a new spatial redistribution of production, according to the obsolescence of European, North American and Canadian industries, and the insertion of hardwood pulp in different stages of production. In relation to the paper industry, the results suggest a scenario not as promising as for the pulp one, even though domestic market may constitute a major boost to the industry.

Keywords: Forests; forest economics; exports; international trade.
\end{abstract}

\section{INTRODUÇÃO}

O mercado global de produtos florestais apresentou, no período 2000 a 2008 , um vigoroso incremento, durante o qual as exportações mundiais cresceram em torno de $50 \%$. Já no ano de 2009 , em decorrência da crise internacional, houve um forte recuo aos níveis observados em 2005 (TORESAN, 2012). A partir do ano de 2010, aconteceu um processo de recuperação, principalmente no mercado mundial de celulose, respaldado pela retomada das compras por parte da China e pelo terremoto no Chile, que provocou uma queda nas exportações daquele país, favorecendo o Brasil. Cabe destacar que três países vêm se sobressaindo na comercialização de produtos florestais: a China, a Rússia e o Brasil, que apresenta importantes vantagens competitivas, entre as quais condições climáticas favoráveis (quantidade de luz solar), a extensão territorial (quantidade e qualidade do solo) e, principalmente, uma tecnologia florestal avançada, a biotecnologia (DORES et al., 2006; MATTOS; VALENÇA, 2009; BIAZUS et al., 2010). 
Os principais produtores de celulose de mercado são os Estados Unidos, a China e o Canadá, que, juntos, responderam por metade da produção total de quase 175 milhões de toneladas no ano de 2009 (FOOD AND AGRICULTURE ORGANIZATION OF THE UNITED NATIONS (FAO), 2011). Isoladamente, o Brasil produziu quase 14 milhões de toneladas, ou $8 \%$ do total mundial. As projeções elaboradas pelo Ministério da Agricultura, Pecuária e Abastecimento (MAPA), citadas por Toresan (2012), indicam que o Brasil passará a ser o segundo maior produtor no ano de 2020, com cerca de 20 milhões de toneladas, em função da produção de celulose de fibra curta, na qual o país é o líder mundial na produção baseada no eucalipto.

No caso da elaboração do papel, a China detém o primeiro posto, com 90 milhões de toneladas, seguida pelos Estados Unidos, com 72 milhões de toneladas; somados, foram responsáveis por quase $43 \%$ do total, estimado em 377 milhões de toneladas (2009). O Brasil, que apresenta como característica industrial a operação em plantas de pequena escala, tornando-se mais vulnerável ao poder de mercado dos grandes produtores internacionais, participou com 2,6\% do mercado, ou 9,7 milhões de toneladas, ocupando a nona posição no mesmo período.

Este artigo parte do pressuposto de que a competitividade florestal brasileira proporciona à indústria de celulose e papel significativas vantagens comparativas, com crescimento da produção e ganhos no comércio internacional, muito embora o setor não esteja imune às crises mundiais. O objetivo é apresentar uma visão geral do setor de celulose e papel no Brasil, através de três seções: na primeira, são apresentados os materiais e métodos; na segunda, os resultados; e na terceira, as conclusões.

\section{MATERIAL E MÉTODOS}

\section{Modelo teórico}

Na elaboração do panorama da indústria de celulose e papel, relacionando as características da estrutura industrial, o desempenho e o comportamento do setor no comércio internacional, foi utilizado o modelo "estrutura-conduta-desempenho".

Na visão de Possas (1990), as explicações acerca do desempenho das empresas pertencentes a uma indústria podem ser assinaladas pela "tríade concentração-barreiras à entrada-lucratividade". Nesse contexto, o entendimento da indústria deve considerar, no estudo teórico, como as relações entre as organizações de mercado e a conduta dos compradores e dos vendedores afetam o desempenho econômico de um país, pois existe uma relação causal entre a estrutura de mercado, a conduta das firmas e o desempenho das mesmas.

Na qualificação da estrutura, Scherer (1979) argumenta que certas variáveis a que os teóricos do preço dão grande ênfase são estudadas no âmbito vasto da estrutura de mercado, que abrange características como o número e a classificação, segundo o tamanho, de vendedores e compradores, o grau de padronização versus diferenciação dos produtos e a presença ou ausência de barreiras à entrada de vendedores adicionais no mercado.

A conduta depende da estrutura e está relacionada com o preço, com o tipo de produto, com as inovações e com os acordos legais. Já o desempenho depende da conduta e inclui as variáveis alocativas e produtivas, a qualidade do produto e os avanços tecnológicos. As políticas governamentais, a política cambial, a política fiscal e a política monetária, também afetam o desempenho das empresas.

\section{Metodologia}

No estudo da estrutura de mercado, foi utilizada a classificação proposta por Scherer (1979). Na investigação da conduta, foram consideradas as inovações tecnológicas, tendo como base a literatura existente, sendo também examinada a capacidade efetiva de utilização. O desempenho foi tabulado com base nas exportações, no preço médio das exportações e no destino das exportações.

A pesquisa exploratória, de cunho documental, se alicerçou em dados secundários obtidos junto aos bancos estatísticos do Ministério do Desenvolvimento, Indústria e Comércio Exterior (MDIC, 2012), da Associação Brasileira de Celulose e Papel (BRACELPA, 2011) e da FAO, (2011).

A distinção das variáveis foi demarcada em função do nível de produção, em milhões de toneladas, da capacidade real de utilização, em termos percentuais, e da composição da produção, em termos do tipo de produto, disponibilizados pela BRACELPA (2011). As exportações e importações, em milhões de dólares norte-americanos, e o destino da produção, a localização geográfica, definidos com base no sistema Aliceweb (MDIC, 2012), no qual o país de destino é aquele conhecido no momento do despacho aduaneiro como o último país para onde se encaminham os bens, complementam as variáveis. 
Conceitualmente, a capacidade real de utilização indica o quanto do volume efetivo da produção está sendo utilizado. No caso de aumento da demanda, a planta pode ser aproveitada até o limite superior tecnológico, e após esse limite a produção pode progredir com ampliação da atual ou a construção de uma nova: capacidade real de utilização $=$ (produção / capacidade da produção) $\times 100$. O preço das exportações permite a observação do esforço necessário para que o exportador aumente ou mantenha 0 nível das receitas, em que: preço das exportações = exportações (em US\$) / exportações $(\mathrm{em} \mathrm{kg}$ ). $\mathrm{O}$ período de investigação compreende os anos 2001 até 2011.

\section{RESULTADOS}

\section{Setor de produtos florestais}

Condições climáticas favoráveis, expressivos investimentos em pesquisa e desenvolvimento, forte organização empresarial e mão de obra altamente qualificada têm possibilitado ao Brasil a obtenção de elevados índices de produtividade das florestas. Simultaneamente, os avanços tecnológicos na genética, na biotecnologia e na manipulação de matérias-primas, além do planejamento socioambiental e da adoção de um eficiente padrão de rotação das florestas plantadas, inegavelmente têm permitido uma conjugação eficaz de produtividade e tecnologia.

Para exemplificar, uma das vantagens competitivas que o Brasil detém, especificamente no fator de tecnologia florestal, está no reduzido tempo de rotação e no elevado rendimento médio da espécie fornecedora de celulose de fibra curta, no caso, o eucalipto. Com um ciclo de rotação de sete anos e rendimento médio de $44 \mathrm{~m}^{3} / \mathrm{ha} / \mathrm{ano}$, na comparação do Brasil com outros países evidenciam-se as primazias. No caso da África do Sul, os indicadores apontam de 8 a 10 anos de ciclo e rendimento de $20 \mathrm{~m}^{3} / \mathrm{ha} / \mathrm{ano}$; no caso do Chile, um ciclo de 10 a 12 anos e $25 \mathrm{~m}^{3} / \mathrm{ha} / \mathrm{ano}$; e no caso de Portugal, um ciclo de 12 a 15 anos e $12 \mathrm{~m}^{3} / \mathrm{ha} /$ ano.

$\mathrm{Na}$ análise das espécies de um gênero com fibras longas, o Pinus spp., o Brasil também apresenta vantagens na rotação de 15 anos e no rendimento médio de $38 \mathrm{~m}^{3} / \mathrm{ha} /$ ano, quando comparados aos resultados observados no Chile e na Nova Zelândia com Pinus radiata, cuja rotação é de 25 anos e o rendimento médio de $22 \mathrm{~m}^{3} / \mathrm{ha} / \mathrm{ano}$; aos observados nos Estados Unidos com Pinus elliotti e Pinus taeda, cuja rotação é de 25 anos e o rendimento médio de $10 \mathrm{~m}^{3} / \mathrm{ha} / \mathrm{ano}$; e aos observados no Canadá com Pinus oregon, cuja rotação é de 45 anos e o rendimento de $7 \mathrm{~m}^{3} / \mathrm{ha} / \mathrm{ano}$.

Da cadeia produtiva do setor de produtos florestais, no segmento de madeira em toras derivam outras três divisões, sendo que no segmento de celulose e pastas encontram-se as indústrias de celulose e papel (Figura 1).

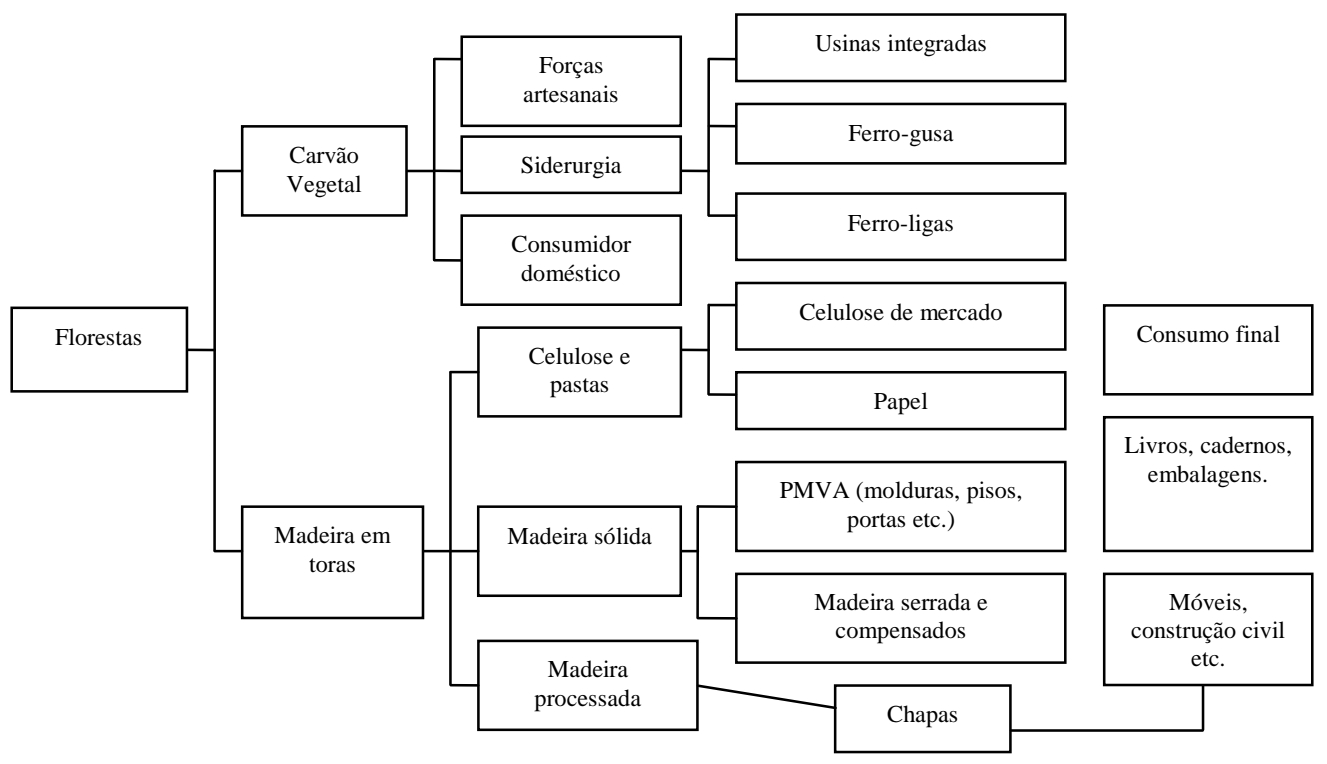

Figura 1. Cadeia produtiva do setor de produtos florestais.

Figure 1. Supply chain industry of forest products.

Fonte: Dores et al. (2006). 
A importância dos produtores florestais para a economia brasileira pode ser corroborada pelos dados da FAO (2011), que apontam a Finlândia, a Suécia, o Canadá e o Brasil como os países que obtêm os maiores ganhos relativos em suas florestas, principalmente no que se refere à geração de empregos $\mathrm{e}$ participação no Valor Adicionado (VA) em cada etapa das unidades produtivas. No caso brasileiro, os produtos florestais geram $2,8 \%$ do valor adicionado bruto e $1,3 \%$ dos empregos.

\section{Setor de celulose}

O segmento de fibras ou celulose pode ser classificado em subgrupos, conforme observado na figura 2, considerando-se as seguintes variáveis: tipo de processamento, origem e destinação da produção.

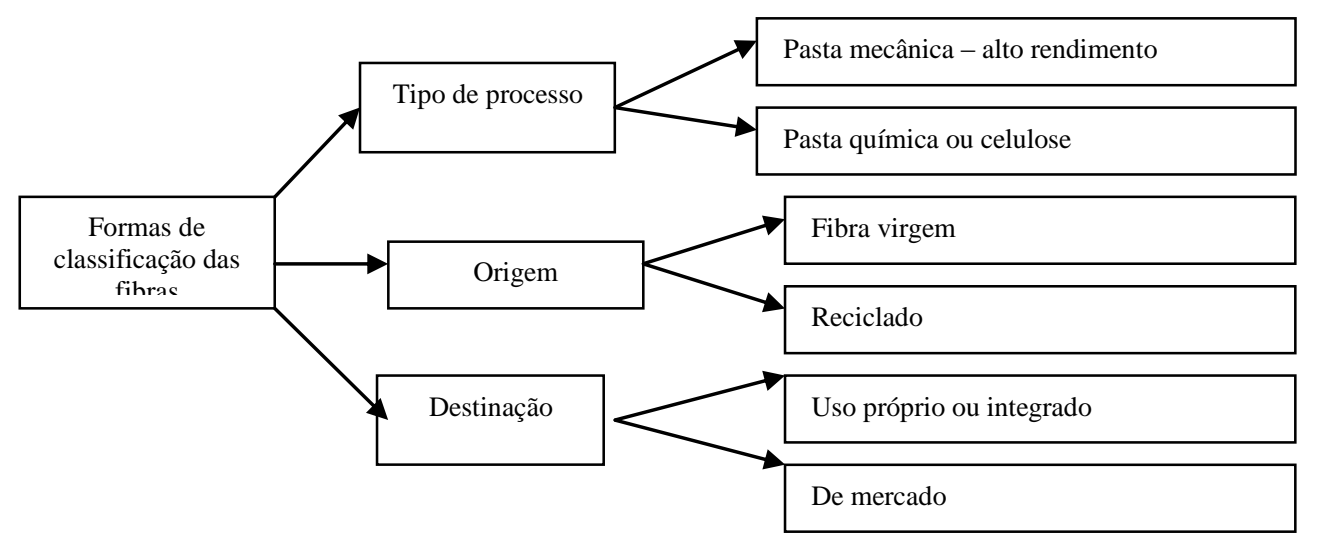

Figura 2 Classificação do setor de fibras.

Figure 2. Classification of fibers sector.

Fonte: Dores et al. (2006).

As árvores coníferas e folhosas, como, por exemplo, o pinus e o eucalipto, ou as plantas que apresentam grandes quantidades de celulose no talo, como a cana-de-açúcar, são adequadas para a obtenção da pasta de celulose. Por sua vez, a pasta mecânica de alto rendimento - high yield pulp (PAR), se caracteriza pelo fato de que, durante a fabricação, a madeira sofre desgastes físicos, objetivando reduzir as fibras na presença de pouco ou nenhum tratamento químico. Esse processo resulta em um alto rendimento na relação pasta/madeira, com cerca de 80 a $95 \%$ de aproveitamento. Seu uso mais frequente acontece na produção de papel de imprensa e, quando branqueada, obtendo-se a pasta termomecânica (thermomechanical pulp) ou a pasta quimiotermomecânica (chemi-thermomechanical pulp), pode ser utilizada na produção de papel de imprimir e de escrever. Com combinações químicas de alguns elementos, é possível obter as pastas químicas ou de celulose, nas quais há uma separação das fibras celulósicas da lignina. Os processos sulfato e sulfito permitem a consecução da celulose sulfato ou kraft e da celulose sulfito (BIAZUS et al., 2010).

No que se refere à origem das fibras, podem ser fibras de celulose virgens ou recicladas. As primeiras são conseguidas diretamente da madeira, pelo processo de decomposição de forma mecânica, química ou térmica, e as fibras recicladas, por sua vez, são obtidas de aparas de papel ou da reciclagem de papéis usados.

Já na destinação, as fibras podem ser classificadas como de uso próprio ou integrado e de mercado. No primeiro caso, uso próprio ou integrado, as pastas são diretamente transformadas em papel, e no segundo caso, de mercado, as pastas passam por processos de secagem e, após a formação de folhas de fibras, são cortadas, empacotadas e distribuídas para os fabricantes de papel.

Uma outra característica importante no segmento de celulose é a divisão técnica entre as chamadas fibras curtas e as fibras longas. As fibras curtas apresentam comprimento entre 0,5 e $1,5 \mathrm{~mm}$, com características de opacidade e de maciez mecânica, tendo como principais usos os papéis sanitários, os papéis de imprimir, os papéis de escrever com maior aderência às tintas e alguns tipos de cartões. As chamadas fibras longas apresentam comprimento superior a $3,0 \mathrm{~mm}$, com características de maior resistência mecânica, tendo como usos essenciais os papéis de embalagem, de imprensa, o papelão 
ondulado e outros tipos de cartões. No Brasil, conforme relatado, a madeira de eucalipto é base para a obtenção das fibras curtas e a madeira de pinus é a base para a obtenção das fibras longas.

$\mathrm{Na}$ sua estruturação, o setor de celulose se caracteriza como sendo um oligopólio concentrado com produto homogêneo, em que a condição de ser intensivo em capital, com elevados investimentos e economias de escala de produção, se constitui em barreira à entrada. Outras duas distinções, também, representam barreiras à entrada: o comportamento cíclico dos preços e os grandes fornecedores mundiais de equipamentos.

Segundo Biazus et al. (2010), uma fábrica de celulose nova no Brasil tem capacidade técnica estimada entre 1,0 e 1,5 milhão de toneladas/ano, o que implica investimentos da ordem de até US\$ 4 bilhões. Em função disso, a indústria apresenta o determinante de ser concentrada, sendo que, conforme os mesmos autores, 56 empresas foram responsáveis por toda a produção de celulose, das quais cinco empresas - Fibria, Suzano, Klabin, Cenibra e International Paper do Brasil - responderam por mais de $73 \%$ da produção. Regionalmente, a produção está distribuída entre os estados do Espírito Santo, Minas Gerais, São Paulo, Bahia, Amapá e Rio Grande do Sul. Em 2013, o estado do Mato Grosso do Sul deve integrar o conjunto de produtores, com o início das atividades do grupo Eldorado.

Os maiores produtores mundiais, no ano de 2011, foram os Estados Unidos, com $26 \%$ do total, a China, com 12\%, o Canadá, com 10\%, o Brasil, com 8\%, e a Suécia, com 6\%. O Brasil passou a ser uma referência internacional entre os produtores de celulose não só pelo volume físico, mas também pelo uso de práticas sustentáveis, pois $100 \%$ da produção de celulose advêm de florestas plantadas, de recursos renováveis.

Na composição da oferta mundial de celulose, há predominância do tipo branqueada, que pode ser tanto de fibra curta quanto de fibra longa. A procura mundial está concentrada nos Estados Unidos, na Europa, principalmente na Alemanha, e na China, que também são grandes produtores de papel. Quando, no exame da demanda, se leva em consideração a fibra de celulose virgem, 12 países concentram $80 \%$ do consumo. Por sua vez, quando a análise recai sobre a fibra de celulose reciclada, a concentração de mercado passa a ser de 90\%, dividida entre dois países: China e Índia.

\section{Setor de papel}

No início, a indústria de papel brasileira se limitava a produzir utilizando papéis descartados. Posteriormente foram introduzidas matérias-primas virgens importadas, principalmente as fibras longas. Na década de 1970, a indústria começou a produzir parte da celulose utilizada e a misturá-la com a celulose importada.

Os principais papéis produzidos são os de imprimir e escrever, os de embalagens, os sanitários, os cartões e os de imprensa. Há predominância de pequenas e médias empresas, com foco no mercado interno, na produção de papéis sanitários, papéis especiais e papelão ondulado. Por sua vez, no caso da produção de papéis de escrever, kraftliner (embalagens) e cartão, existe uma estrutura formada por empresas de grande porte, cujo objetivo principal é atender o mercado externo, embora Dores et al. (2006) citem que as dificuldades de logística, distância e modais de distribuição constituam-se nos maiores entraves ao aumento da participação das empresas locais nos mercados externos.

Em termos espaciais, existe uma convergência da produção de papéis nas regiões Sul e Sudeste. Os papéis de embalagem são elaborados principalmente nos estados de Santa Catarina, Paraná e São Paulo, que, juntos, detêm $81 \%$ do total. Os papéis de imprimir e escrever são manufaturados no estado de São Paulo, que representa $74 \%$ do total. O papel de imprensa é fabricado exclusivamente no estado Paraná, onde estão localizadas as duas únicas unidades produtoras: a Klabin e a Pisa. Os cartões são produzidos nos estados de São Paulo, com 55\% do total, e Paraná, com 25\%. Na manufatura dos papéis sanitários, há uma concentração de 68\% nos estados de Santa Catarina e São Paulo, e 21\%, divididos em partes igualitárias, nos estados do Paraná, Rio de Janeiro e Minas Gerais.

Um traço peculiar do setor de papel na última década foi a concentração industrial, em que as grandes empresas internacionais ampliaram seus canais de distribuição e passaram a operar em mercados com elevados potenciais de crescimento. A combinação de baixo custo da matéria-prima com as boas perspectivas para mercado interno tem proporcionado ao Brasil uma condição de grande atratividade para os investimentos internacionais, visto que o consumo per capita brasileiro, de 44,2 kg/habitante/ano, é inferior à média mundial, de $57,5 \mathrm{~kg} / \mathrm{habitante} / \mathrm{ano}$. Isoladamente, quando comparado aos níveis de 
consumo da Finlândia, 339,1 kg/habitante/ano, e dos Estados Unidos, 263,3 kg/habitante/ano, o potencial de crescimento parece ser ainda maior (BRACELPA, 2011).

Os maiores produtores em 2011 foram a China (24\%), os Estados Unidos (19\%), o Japão (7\%), a Alemanha (6\%), o Canadá $(3 \%)$ e o Brasil (2,5\%), considerando que a demanda interna é inferior à produção nacional, com exceção do papel imprensa. Os principais mercados consumidores de papéis no mundo estão situados na Ásia (37\%) e na América do Norte (28\%).

\section{Caracterização da produção de celulose e papel}

No início dos anos 2000, o programa de investimentos do setor de celulose e papel previa montantes financeiros da ordem de US\$ 1,9 bilhão para o período 2003/2012 (BRACELPA, 2011). No mesmo período, a evolução média da formação bruta de capital fixo foi de $16,92 \%$ do PIB, sendo que o setor privado foi responsável por $80,5 \%$ desse valor, ficando o setor de celulose e papel com $0,1 \%$ do total investido pelo setor privado (SECRETARIA DO TESOURO NACIONAL (STN), 2012).

Os resultados da tabela 1 apontam para uma expansão média de 6,08\% na produção de celulose e uma expansão média de 2,62\% na produção de papel, no período de 2001 a 2011. No mesmo momento temporal, o crescimento médio do PIB brasileiro foi de 3,6\% (STN, 2012).

No caso da produção de celulose, a elevada taxa de crescimento foi sustentada pelo aumento da inserção internacional da celulose de fibra curta, na qual o país apresenta a liderança no segmento desde o ano de 2002, com incremento na demanda dos países europeus e dos Estados Unidos. O consumo de celulose de fibra curta aumentou 13,4\%, estabelecendo no ano seguinte um equilíbrio na demanda internacional entre a fibra longa, até então dominante, e a fibra curta. Um outro momento de destaque na produção de celulose no Brasil se deu no triênio 2005/2006/2007, cujas taxas de crescimento se situaram próximas dos $8 \%$ ao ano. A combinação de ganhos de produtividade com expansão da capacidade produtiva, atrelados à desvalorização da moeda local, o real, contribuíram para os resultados.

No ano de 2009, quando a variação do PIB brasileiro foi negativa $(-0,6 \%)$, o setor de celulose aumentou em grandeza quase 5\%, com evolução positiva da capacidade instalada em 9,5\%, em relação ao ano anterior. As empresas instaladas no Brasil se beneficiaram da queda programada na produção dos maiores fabricantes mundiais em quase dois milhões de toneladas, que objetivavam no mínimo manter o nível de preços no mercado. Já no ano de 2011 , a produção aumentou apenas $0,25 \%$, e a capacidade produtiva, 2,54\%, o equivalente a mais de 37 mil toneladas, em função do enfraquecimento da atividade econômica na zona do Euro, que recuou $-10,64 \%$, e das reduções nas exportações para a África e para a Ásia, que retrocederam conjuntamente $-14,2 \%$, segundo a base de dados do Banco Mundial (WORLD BANK, 2012). A região com a representação de maior mercado para a celulose brasileira continua sendo a Europa e a região com maiores destinos tem sido a América Latina.

No Brasil, a produção de celulose de fibra curta, que no caso brasileiro demonstra ser 2,5 vezes mais eficiente que a fabricada na África do Sul e no Chile e 6,3 vezes mais eficiente que a elaborada em Portugal, quando comparados o rendimento médio por $\mathrm{m}^{3} / \mathrm{ha} / \mathrm{ano}$, apesar da comprovada eficácia, apresenta uma forte polêmica, pois o eucalipto incentiva a opção pela monocultura, que é prejudicial à biodiversidade.

Com relação à celulose de fibra longa, a estrutura produtiva brasileira está sustentada na madeira de Pinus spp., que consegue ser 2,9 vezes mais eficiente que a produzida no Chile e na Nova Zelândia, que cultivam o Pinus radiata, 6,4 vezes mais eficiente que a produzida nos Estados Unidos, que cultiva o Pinus elliotti e Pinus taeda, e 11,2 vezes mais eficientes que o Canadá, que cultiva o Pinus oregon.

Embora tradicionalmente a celulose de fibra longa tenha níveis de preços mais elevados que a celulose de fibra curta, que, em alguns momentos, foram superiores a 40\% (FOEX Indexes Ltd (FOEX), 2012), a manufatura de celulose de fibra curta gradativamente vem aumentando a participação no mercado, em função de alterações ocorridas com o processo de reestruturação produtiva das fábricas europeias, norte-americanas e canadenses, que passaram a utilizar maiores quantidades de celulose de fibra curta, impactando positivamente no plantio florestal brasileiro.

No ano de 2010, por exemplo, a cultura do eucalipto (fibra curta) esteve presente em $91,2 \%$ dos cultivos, distribuídos nos três estados da região Sul, na região Sudeste, exceto no Rio de Janeiro, na região Nordeste (na Bahia) e na região Centro-Oeste (no Mato Grosso do Sul). A participação relativa da celulose de fibra longa, que foi de quase $20 \%$ no início do ciclo de análise, reduziu-se para pouco mais de 
$11 \%$ no final do período, cabendo ressaltar que a produtividade média do eucalipto é $15,4 \%$ superior à do Pinus spp.

Na produção de papel (Tabela 1), observa-se que, durante todo o período de análise, as taxas foram positivas, com incremento médio de $2,62 \%$. Na capacidade efetiva, a evolução média foi de $1,34 \%$. As perspectivas políticas do setor para o ano de 2003 eram ruins, e algumas plantas foram desativadas. Naquele ano, o PIB brasileiro cresceu $1,2 \%$ e os indicadores de investimento privado, através da formação bruta de capital fixo, foram os menores da série histórica da Secretaria do Tesouro Nacional (STN, 2011), com 12,7\% do PIB. A mudança política no comando do país contribuiu fortemente para a deflagração de um cenário de incertezas, no qual os investimentos foram protelados.

Tabela 1. Produção e capacidade de utilização da indústria de celulose e papel do Brasil - 2001 a 2011.

Table 1. Production and utilization capacity of pulp and paper industry in Brazil - 2001 to 2011.

\begin{tabular}{ccccc}
\hline \multirow{2}{*}{ Ano } & \multicolumn{2}{c}{ Celulose } & Papel \\
\cline { 2 - 5 } & $\begin{array}{c}\text { Produção } \\
\text { (mil ton.) }\end{array}$ & $\begin{array}{c}\text { Capacidade de } \\
\text { Utilização (\%) }\end{array}$ & $\begin{array}{c}\text { Produção } \\
\text { (mil ton.) }\end{array}$ & $\begin{array}{c}\text { Capacidade de } \\
\text { utilização (\%) }\end{array}$ \\
\hline 2001 & 7.412 & 99,0 & 7.438 & 83,0 \\
2002 & 8.021 & 97,5 & 7.774 & 82,4 \\
2003 & 9.096 & 99,5 & 7.916 & 83,6 \\
2004 & 9.620 & 98,9 & 8.452 & 87,3 \\
2005 & 10.352 & 96,2 & 8.597 & 86,5 \\
2006 & 11.180 & 99,2 & 8.725 & 86,6 \\
2007 & 11.998 & 95,8 & 9.008 & 86,5 \\
2008 & 12.697 & 96,2 & 9.409 & 85,9 \\
2009 & 13.315 & 91,8 & 9.428 & 91,1 \\
2010 & 14.164 & 96,9 & 9.844 & 86,7 \\
2011 & 14.200 & 97,0 & 9.887 & 87,0 \\
\hline
\end{tabular}

Fonte: Elaborada pelos autores com dados da BRACELPA (2011).

Durante a crise internacional de 2009 , a produção de papel se elevou em $0,2 \%$, mas a capacidade efetiva da indústria brasileira se reduziu em $-5,3 \%$. Na ocasião, algumas empresas do setor protegeram suas finanças com investimentos em derivativos. Outras apresentaram aumentos das dívidas, em função das desvalorizações da moeda local. Como consequência do elevado endividamento em dólar norteamericano, a Klabin encerrou as atividades em uma fábrica de papel reciclado instalada no estado de Minas Gerais e outras reduziram o nível de atividade em função da imobilização financeira na formação de estoques próximas dos 50 dias, quando o período mais adequado é de aproximadamente 30 dias.

$\mathrm{Na}$ hierarquização da composição da produção de papel no Brasil, os papéis para embalagem ocuparam quase $50 \%$ da estrutura produtiva, e os papéis de imprimir e escrever, quase $30 \%$ (Tabela 4). Residualmente, os papéis sanitários, os papéis-cartão e os classificados como outros papéis responderam por aproximadamente $20 \%$. Nessas composições, conforme relatado, a demanda interna é inferior à produção nacional, existindo um excedente que é exportado.

No caso do papel para imprensa, a produção interna atendeu pouco mais de $30 \%$ do mercado (Dores et al., 2006), sendo o restante suprido por importações oriundas principalmente do Canadá. Os dois únicos produtores nacionais, as empresas Klabin e Pisa, segundo Biazus et al. (2010), não têm realizado os desembolsos financeiros que permitam acompanhar o crescimento da demanda interna, embora o volume importado justifique maiores investimentos. Um outro fator que desestimula a produção interna é o benefício que a Constituição brasileira concede aos importadores de não pagarem tributos, o que tem se tornado mais um obstáculo para a ampliação/implantação de novas unidades.

$\mathrm{Na}$ análise do destino da produção de celulose e papel no Brasil (Tabela 2) no intervalo 2007 a 2011, observa-se que, em média, quase $57,6 \%$ da produção de celulose foram exportados, contra pouco mais de $20,2 \%$ da produção de papel.

Já no caso do mercado consumidor interno, em média 32,8\% da celulose produzida abasteceu as empresas locais, evidenciando uma estrutura internacionalizada. No caso do papel, $54,4 \%$ da produção foram direcionados para as empresas locais, que remeteram para o mercado externo. 
Tabela 2. Destino da produção de celulose e papel no Brasil - 2007 a 2011.

Table 2. Destination of the pulp and paper in Brazil - 2007 to 2011.

\begin{tabular}{|c|c|c|c|c|c|c|c|c|c|c|}
\hline \multirow{3}{*}{ Destino } & \multicolumn{5}{|c|}{ Celulose } & \multicolumn{5}{|c|}{ Papel } \\
\hline & \multicolumn{5}{|c|}{ Participação \% } & \multicolumn{5}{|c|}{ Participação \% } \\
\hline & 2007 & 2008 & 2009 & 2010 & 2011 & 2007 & 2008 & 2009 & 2010 & 2011 \\
\hline Exportação & 54,0 & 56,0 & 59,0 & 60,0 & 59,0 & 19,0 & 19,0 & 21,0 & 21,0 & 21,0 \\
\hline Consumo próprio & 10,0 & 9,9 & 8,4 & 9,3 & 10,3 & 24,0 & 24,0 & 26,0 & 25,0 & 26,0 \\
\hline Vendas internas & 36,0 & 34,1 & 32,6 & 30,7 & 30,7 & 57,0 & 55,0 & 54,0 & 53,0 & 53,0 \\
\hline
\end{tabular}

Fonte: Elaborada pelos autores com dados da BRACELPA (2011).

Na classificação do consumo próprio, o setor de celulose utilizou em média 9,5\% do total produzido, enquanto que o setor de papel utilizou em média $25,0 \%$ no processo produtivo.

\section{Exportações e importações de celulose e papel}

As exportações de celulose são classificadas pelo Ministério do Desenvolvimento, Indústria e Comércio Exterior (MDIC, 2012) no grupo dos produtos semimanufaturados. Em média, representaram $14 \%$ no grupo, sendo que as exportações de pasta de celulose foram responsáveis pela quase totalidade dos envios. Quando confrontados os totais gerais exportados pelo Brasil, em todo o período de análise, a participação relativa foi de 2,04\%, representando ao final de 2011 um montante superior a US $\$ 5,0$ bilhões.

Por sua vez, as importações de celulose apresentaram um desempenho bem inferior às importações totais do Brasil. Em média evoluíram 6,7\% ao ano, contra 13,6\% das exportações totais, que denota uma menor dependência da celulose externa, visto que a produção e o consumo internos aumentaram.

Os saldos comerciais da balança de celulose sempre foram positivos (Tabela 3), sendo que as maiores taxas de crescimento aconteceram nos anos de 2003, decorrentes do uso da fibra curta com maior intensidade nas plantas mundiais no ano anterior, e em 2010, em função das reduções na oferta mundial e do incremento das compras por parte da China.

Ocorreu, também, no ano de 2009, a formação do grupo brasileiro Fibria, resultante da aquisição da Aracruz Celulose pela Votorantim Celulose e Papel, constituindo-se na maior empresa de celulose de mercado do mundo, o que em tese dará ao oligopólio o poder adicional da escala de produção e da curva de experiência.

Em termos relativos, as exportações de papel representaram 1,2\% do total exportado pelo Brasil, enquanto que as importações em média foram de $0,9 \%$ do total importado. No último ano, a corrente de comércio de celulose atingiu US\$ 5,3 bilhões e foi 36\% superior à verificada no segmento de papel, cuja cifra atingiu US\$ 3,9 bilhões (Tabelas 3 e 4).

Tabela 3. Evolução das Exportações e Importações de Celulose do Brasil - 2001 a 2011.

Table 3. Exports and Imports of pulp in Brazil - 2001 to 2011.

\begin{tabular}{lcccc}
\hline \multirow{2}{*}{ Período } & \multicolumn{2}{c}{ Exportação } & \multicolumn{2}{c}{ Importação } \\
\cline { 2 - 5 } & $\begin{array}{c}\text { Valor } \\
\text { (milhões de US\$) }\end{array}$ & $\begin{array}{c}\text { Participação no total } \\
\text { do Brasil (\%) }\end{array}$ & $\begin{array}{c}\text { Valor } \\
\text { (milhões de US\$) }\end{array}$ & $\begin{array}{c}\text { Participação no total } \\
\text { do Brasil (\%) }\end{array}$ \\
\hline 2001 & 1.248 & 2,1 & 183 & 0,3 \\
2002 & 1.161 & 1,6 & 172 & 0,4 \\
2003 & 1.744 & 2,9 & 158 & 0,3 \\
2004 & 1.722 & 1,8 & 195 & 0,3 \\
2005 & 2.034 & 1,7 & 210 & 0,3 \\
2006 & 2.484 & 1,8 & 213 & 0,2 \\
2007 & 3.024 & 1,9 & 232 & 0,2 \\
2008 & 3.917 & 2,0 & 274 & 0,2 \\
2009 & 3.315 & 2,2 & 242 & 0,2 \\
2010 & 4.762 & 2,4 & 360 & 0,2 \\
2011 & 5.002 & 2,0 & 374 & 0,2 \\
\hline
\end{tabular}

Fonte: MDIC (2012). 
As magnitudes financeiras das exportações de papel efetuadas pelo Brasil, classificadas no grupo dos produtos industrializados, no subgrupo de produtos manufaturados, são inferiores às obtidas com as exportações de celulose (Tabela 4). As importações de papel foram mais representativas do que as importações de celulose, denunciando, principalmente, o grande volume de importação de papel imprensa, equivalente a dois terços do consumo interno.

Tabela 4. Exportações e importações de papel do Brasil - 2001 a 2011.

Table 4. Exports and imports of paper in Brazil - 2001 to 2011.

\begin{tabular}{|c|c|c|c|c|}
\hline \multirow[b]{2}{*}{ Período } & \multicolumn{2}{|c|}{ Exportação } & \multicolumn{2}{|c|}{ Importação } \\
\hline & $\begin{array}{c}\text { Valor } \\
\text { (milhões de US\$) }\end{array}$ & $\begin{array}{c}\text { Participação no Total } \\
\text { Brasil (\%) }\end{array}$ & $\begin{array}{c}\text { Valor } \\
\text { (milhões de US\$) }\end{array}$ & $\begin{array}{c}\text { Participação no } \\
\text { Total do Brasil (\%) }\end{array}$ \\
\hline 2001 & 943 & 1,6 & 589 & 1,1 \\
\hline 2002 & 894 & 1,2 & 422 & 0,8 \\
\hline 2003 & 1.087 & 1,8 & 403 & 0,9 \\
\hline 2004 & 1.187 & 1,2 & 563 & 0,9 \\
\hline 2005 & 1.371 & 1,2 & 654 & 0,9 \\
\hline 2006 & 1.521 & 1,1 & 912 & 1,0 \\
\hline 2007 & 1.702 & 1,0 & 1.086 & 0,9 \\
\hline 2008 & 1.920 & 0,9 & 1.437 & 0,8 \\
\hline 2009 & 1.686 & 1,1 & 1.097 & 0,9 \\
\hline 2010 & 2.008 & 1,0 & 1.539 & 0,7 \\
\hline 2011 & 2.188 & 0,8 & 1.754 & 0,9 \\
\hline
\end{tabular}

Fonte: MDIC (2012).

Merece destaque o fato de que os superávits gerados com a comercialização do papel são bem inferiores aos verificados no caso da celulose. No início do período, o saldo comercial da celulose foi três vezes maior do que o do papel. Dos anos de 2002 até 2005, a diferença situou-se na faixa de 2,5 vezes. A partir de 2006, existiu um forte incremento e a diferença chegou a 7,5 vezes no ano de 2008 . A crise do ano seguinte alterou novamente a proporcionalidade entre o saldo das exportações de celulose e o saldo das exportações de papel, com maiores impactos negativos para a celulose, que tem como destino preferencial os países centrais, como a Bélgica, a Holanda e a Itália, seriamente afetados pela crise financeira. Por sua vez, as exportações de papel estão voltadas para os países da América Latina, principalmente a Argentina e o Chile, em que os impactos financeiros não foram imediatos. Já no ano de 2011, o saldo das exportações de celulose atingiu a proporção de 10 vezes maior que o saldo das exportações de papel, cujas magnitudes foram de US \$ 4,6 bilhões contra US\$ 434 milhões, respectivamente.

$\mathrm{Na}$ análise da tabela 5, cujas ponderações acerca do destino das exportações de celulose e papel estão expressas, observa-se que, no caso da celulose, a Europa, em 2001, respondeu por $40 \%$ do total, e em 2011 por 43,6\%, constituindo-se no principal mercado. A América do Norte perdeu importância relativa, passando de $32 \%$ para $17,6 \%$, enquanto que a China passou a responder por $27 \%$ dos destinos, o que compensou financeiramente os recuos da América do Norte, da Ásia e da Oceania. Somadas à Europa, a América do Norte e a China representaram 88,2\% dos destinos das exportações brasileiras de celulose, o que resultou numa receita de US\$ 4,4 bilhões em 2011.

No destino das exportações de papel, o perfil é pouco diferente. A América Latina, que respondeu por $51 \%$ em 1998, passou a responder por 55,3\% do total financeiro dos destinos, o equivalente a US\$1,2 bilhão, enquanto que a Europa reduziu sua participação para 17,7\% e a América do Norte para $10 \%$.

O destaque novamente foi a China, que passou a figurar como o quinto destino das exportações brasileiras de papel, divididas entre o papel de imprimir e escrever, o kraftliner e o cartão, que são demandados por economias em crescimento, como é o caso chinês, que em média evoluiu 16,7\% ao ano (WORLD BANK, 2012).

\section{Preço das exportações}

Nos primeiros cinco anos, a oscilação dos preços foi quase nula, em função da grande oferta internacional (Tabela 6). Os resultados no final do período podem ser justificados pela redução na oferta 
global de celulose, no caso o Chile, e pelo aumento na demanda nos principais mercados consumidores, principalmente a China, conforme relatado.

Tabela 5. Exportações brasileiras de papel e celulose por destino - (1998 a 2011).

Table 5. Exports of brazilian pulp and paper by destination - (1998 to 2011).

\begin{tabular}{|c|c|c|c|c|}
\hline \multirow{3}{*}{ Destino } & \multicolumn{4}{|c|}{ Participação (\%) } \\
\hline & \multicolumn{2}{|c|}{ Celulose } & \multicolumn{2}{|c|}{ Papel } \\
\hline & 1998 & 2011 & 1998 & 2011 \\
\hline América Latina & 2,0 & 1,2 & 51,0 & 55,3 \\
\hline Europa & 40,0 & 43,6 & 20,0 & 17,7 \\
\hline América do Norte & 32,0 & 17,6 & 11,0 & 10,0 \\
\hline África & 0,1 & 0,1 & 7,0 & 4,7 \\
\hline Ásia / Oceania & 25,0 & 10,9 & 12,0 & 6,7 \\
\hline China & - & 27,0 & - & 5,4 \\
\hline Outros & 0,9 & - & - & 0,2 \\
\hline Total & 100,0 & 100,0 & 100,0 & 100,0 \\
\hline
\end{tabular}

Fonte: Elaborada pelos autores com dados da BRACELPA (2011).

Tabela 6. Preço médio das exportações de celulose e papel do Brasil - 2001 a 2011.

Table 6. Average price exports of Brazilian Pulp and Paper - 2001 to 2011.

\begin{tabular}{lcccc}
\hline & \multicolumn{4}{c}{ Produtos industrializados } \\
\cline { 2 - 5 } Ano & \multicolumn{2}{c}{ Produtos semimanufaturados } & \multicolumn{2}{c}{ Produtos manufaturados } \\
\cline { 2 - 5 } & $\begin{array}{c}\text { Preço médio do } \\
\text { total (US\$/kg) }\end{array}$ & $\begin{array}{c}\text { Preço médio da } \\
\text { celulose } \mathbf{( U S} \mathbf{/ k g})\end{array}$ & $\begin{array}{c}\text { Preço médio do total } \\
\text { (US\$/kg) }\end{array}$ & $\begin{array}{c}\text { Preço médio do } \\
\text { papel (US\$/kg) }\end{array}$ \\
\hline 2001 & 0,31 & 0,38 & 1,03 & 0,69 \\
2002 & 0,30 & 0,35 & 0,93 & 0,61 \\
2003 & 0,34 & 0,39 & 0,94 & 0,61 \\
2004 & 0,38 & 0,35 & 1,07 & 0,64 \\
2005 & 0,42 & 0,37 & 1,24 & 0,67 \\
2006 & 0,50 & 0,40 & 1,35 & 0,76 \\
2007 & 0,58 & 0,47 & 1,50 & 0,85 \\
2008 & 0,69 & 0,56 & 1,83 & 0,97 \\
2009 & 0,52 & 0,40 & 1,45 & 0,84 \\
2010 & 0,66 & 0,57 & 1,71 & 0,97 \\
2011 & 0,80 & 0,59 & 2,01 & 1,07 \\
\hline
\end{tabular}

Fonte: Elaborada pelos autores com dados da BRACELPA (2011).

As exportações de celulose apresentaram oscilações no preço médio, que variou de um mínimo de US\$ 0,35, no ano de 2002, até um máximo de US\$ 0,59, no ano de 2011, variação essa superior aos $55 \%$. Por sua vez, analisando os valores agregados, observa-se a existência de um preço médio de US\$ 0,30 , valor mínimo, também observado no ano de 2002, e um valor máximo de US\$ 0,80 , no ano de 2011, cuja diferença atingiu $166 \%$. No ano de 2002, a paridade da moeda local atingiu a maior desvalorização quando comparada ao dólar norte-americano, cujo valor ficou em $\mathrm{R} \$ 3,53$, o que impulsionou as quantidades exportadas, em função do preço do produto nacional ter ficado mais barato em dólar norte-americano. As quantidades exportadas aumentaram mais 10,4\%, enquanto os valores financeiros evoluíram 8,7\%. Já no ano de 2011, apesar da supervalorização da moeda local, a taxa de câmbio acusou paridade de $\mathrm{R} \$ 1,67$ e $\mathrm{R} \$ 1,88$, respectivamente, nos anos de 2010 e 2011. A maior inserção da celulose brasileira de fibra curta nos mercados internacionais se deu em decorrência da menor oferta internacional e, novamente, das grandes aquisições da China, o maior produtor de papel, análogo ao descrito.

Numa análise mais específica, o preço da celulose de fibra longa e de fibra curta praticado na Europa é muito superior aos obtidos pelo Brasil no comércio internacional. No mês de julho de 2010, a celulose de fibra longa foi cotada a US\$ 1,00 o quilograma e a celulose de fibra curta a US\$ $0,94 \mathrm{o}$ quilograma. Ao final do mesmo ano, os preços se estabilizaram nos níveis de US $\$ 0,94$ para a fibra longa e US\$ 0,87 para a fibra curta. Nesse caso, a indústria de celulose internacional demonstra "poder de 
fornecedor" quando comparada à indústria de papel, possibilitando assim a prática de um nível de preços mais elevado, quando comparados aos preços brasileiros.

A agregação de valor com o processo de fabricação do papel, demonstra que o preço médio das exportações de papel, quando comparado com as exportações de celulose, é superior. Em média essa diferença foi de $80,2 \%$, atingindo o pico no ano de 2009, com $110,0 \%$. Confrontando os valores financeiros exportados pelos setores de celulose e papel (Tabelas 3 e 4) com as participações relativas dos respectivos setores no comércio internacional (BRACELPA, 2011), é possível diagnosticar que a eficiência da indústria de papel foi 34,6\%.

Nos valores agregados do grupo de produtos industrializados, subgrupo de manufaturados, os preços médios indicam quase as mesmas tendências de valores mínimos e valores máximos que os observados para o papel, embora a oscilação nos preços do agregado de produtos manufaturados tenha atingido $116,1 \%$, enquanto a variabilidade do papel tenha sido de $75,4 \%$. O nível de competição do setor papel é muito mais acirrado e as empresas mundiais, tais como a International Paper, a Union Camp, a Weyyerhaueser e a MacMillan Bloedel, apresentam elevadas escalas de produção, canais de distribuição preferenciais e custos de capital reduzidos.

\section{CONCLUSÕES}

Com base nos resultados, pode-se concluir que:

- A indústria de celulose e papel instalada no Brasil apresentou um acréscimo na participação do comércio internacional com aumento das exportações, consubstanciado pela existência de importantes vantagens competitivas e variações discretas no preço médio, em função do menor poder de mercado;

- O potencial e a capacidade da indústria de celulose brasileira são bem superiores aos do papel;

- A fibra curta, que tem como matéria-prima base o eucalipto, apresenta vantagens competitivas muito importantes, colocando o Brasil na liderança mundial;

- Num cenário de demanda crescente de alimentos, de biocombustíveis, de fibras e de florestas e com a adoção de um processo de estruturação aos moldes dos chamados "4 F's (Food, Fuel, Fiber, Forests)", as empresas que investirem em biotecnologia e planejamento florestal terão mais possibilidades de uma maior inserção internacional, para o que a adoção de novas técnicas de cultivo e de uso racional dos recursos naturais é imprescindível.

\section{REFERÊNCIAS}

ASSOCIAÇÃO BRASILEIRA DE CELULOSE E PAPEL (BRACELPA). Conjuntura Bracelpa. Disponível em: <http://www.bracelpa.org.br/bra2/?q=node/188>. Acesso em: 10/10/2011.

BIAZUS, A.; Da HORA, A.; LEITE, B. Setorial: Panorama de mercado: celulose. Banco Nacional de Desenvolvimento Econômico e Social (BNDES). Rio de Janeiro, n. 32, p. 311 - 370. 2010.

DORES, A. M. B. das; CHAGAS, F. B. das; MATTOS, R. L. G. de; GONÇALVES, R. M. Papel e Celulose. Panorama Setorial: Setor Florestal, Celulose e Papel. Banco Nacional de Desenvolvimento Econômico e Social (BNDES). Rio de Janeiro, p. 109 - 134. 2006.

FOEX Indexes Ltd. (FOEX). Latest PIX Index Values with Comments. Disponível em: $<$ http://www.foex.fi/index.php?page=pix-pulp-2>. Acesso em: 20/01/2012.

FOOD AND AGRICULTURE ORGANIZATION OF THE UNITED NATIONS (FAO). FAOSTAT. Disponível em: <http://www.faostat3.fao.org/home/index.html>. Acesso em: 10/10/2011.

MATTOS, R. G.; VALENÇA, Antonio C. A. Reestruturação do setor de papel e celulose. Rio de Janeiro: BNDES, p. 253 - 268. 2009.

MINISTÉRIO DO DESENVOLVIMENTO, INDÚSTRIA E COMÉRCIO EXTERIOR (MDIC). Sistema Alice. Disponível em: <http://www.aliceweb2.mdic.gov.br/index/home>. Acesso em: 20/01/2012.

POSSAS, M. L. Estruturas de mercado em oligopólio. São Paulo: Hucitec, 1990. 191 p. 
SCHERER, F. M. Preços industriais: teoria e evidência. Rio de Janeiro: Campus, 1979. 242 p.

SECRETARIA DO TESOURO NACIONAL (STN). Economia brasileira em perspectiva. 12. ed. maio-julho 2011. Disponível em: <https://www.tesouro.fazenda.gov.br/pt/divida-publica-federal>. Acesso em: 10/10/2011.

TORESAN, L. Desempenho do setor florestal. In: VIEIRA, Luiz Marcelino (Coord.). Síntese anual da agricultura de Santa Catarina 2011-2012. Empresa de Pesquisa Agropecuária e Extensão Rural de Santa Catarina. Centro Socioeconômico e Planejamento Agrícola - Epagri/Cepa. Florianópolis, p. 133 153. 2012.

WORLD BANK. World Databank. Disponível em: <http://data.worldbank.org/indicator/NY. GDP.MKTP.KD.ZG>. Acesso em: 20/10/2012. 